\title{
PENGELOLAAN PROGRAM PENDIDIKAN NONFORMAL UNTUK KELOMPOK MASYARAKAT LANJUT USIA
}

Jurnal Pendidikan Luar Sekolah

http://kolokium.ppj.unp.ac.id/index.php

/ kolokium-pls

Jurusan Pendidikan Luar Sekolah

Fakultas IImu Pendidikan

Universitas Negeri Padang

Sumatera Barat, Indonesia

Volume 6, Nomor 1, April 2018

DOI: 10.24036/kolokium-pls.v6i1.2

\author{
Irmawita ${ }^{1,2}$ \\ Jurusan Pendidikan Luar Sekolah, Fakultas Ilmu Pendidikan,Universitas Negeri Padang \\ Email: irmawita@fip.unp.ac.id
}

\begin{abstract}
The essence of national development is to build on a solid foundation and strong foundation in the form of certain conditions in various national life. Community development there are two challenges that need to be considered to build the organization (organization development) and economic development (economic development). In the development of organizations, the organization is the frame work of every form of cooperation to achieve a common goal, therefore it needs to be built on the basis of a democratic, dynamic and harmonious relationship. Likewise with the elderly community groups, based on Boyle's taxonomic thinking about the type of non-formal education is divided into three types: developmental, institutional, and informational. Developmental programs are also called community development programs, where the main program objectives are solving social, economic, cultural, political, and defense and security problems facing the target group through action programs. An instituional program is also called a training program aimed at mastering a set of capabilities (knowledge, attitudes and/or skills) by the target group. While the informational program can be called also with counseling or publicity, aims to achieve a set of information by the target group. Thus the community development program is one of the types of non-formal education programs.
\end{abstract}

Keywords: Program, Education, Nonformal, Elderly

\section{PENDAHULUAN}

Pendidikan untuk semua (educational for all) yang dilandasi oleh filsafat pendidikan sepanjang hayat tidak akan memiliki arti yang mendalam jika layanan kebutuhan pendidikan tidak menyentuh masyarakat lanjut usia. Pendidikan dikatakan berlangsung dari sejak buaian hingga di liang lahat, tidak akan memiliki arti apa-apa jika hanya memusatkan perhatian pada pertumbuhan dan perkembangan manusia saja, akan tetapi harus pula memperhatikan manusia disaat mengalami kemunduran fungsi. Untuk itu dipandang perlu pendidikan yang berorientasi pada sasaran (warga binaan) lanjut usia, mengingat potensi yang dimilikinya baik secara kuantitas maupun secara kualitas, sehingga pendidikan bisa berlangsung sepanjang hayat. 


\section{KAJIAN TEORI}

\section{Fungsi Program Pendidikan Nonformal Bagi Masyarakat Lanjut Usia}

Harapan dari program pendidikan nonformal bagi kelompok masyarakat lanjut usia adalah untuk mewujudkan masa tua yang mampu memberikan keputusan yang terbaik, mampu memenuhi kebutuhan, mampu menghargai orang lain, mampu menghilangkan ketergantungan, minimal dengan pihak lain, sehingga hidup sehat, bahagia, produktif, berdaya guna dan terjadinya peningkatan kemandirian serta peran serta warga belajar lanjut usia di tengah-tengah masyarakat dan keluarga khususnya.

Program Pendidikan nonformal bagi kelompok masyarakat lanjut usia selain memiliki peran, juga memiliki beerbagai fungsi. Pada program pendidikan nonformal untuk masyarakat lanjut usia memiliki fungsi-fungsi yang sama dengan fungsi kurikulum Persistent Life Situtions (Stratemeyer: 1957), (Hilda Taba: 1962), (J Gallan Saylor, William M Alexander, Arthur J.Lewis, 1976) maupun fungsi-fungsi kurikulum pada umumnya (Alexander Inglis dalam Oemar Malik: 2003). Fungsi-fungsi tersebut adalah:

1. Fungsi penyesuaian

Fungsi penyesuaian pada program pendidikan nonformal bagi lanjut usia memandang bahwa individu (lanjut usia) hidup dalam lingkungan, sehingga setiap individu (lanjut usia) harus mampu menyesuaikan diri disebabkan lingkungan tempat individu berintaraksi selalu berubah dan bersifat dinamis.

2. Fungsi pengintegrasian

Fungsi integrasi, memandang bahwa program pendidikan nonformal harus berfungsi mendidik pribadi-pribadi (lanjut usia) yang terintegrasi. Hal tersebut disebabkan individu (lanjut usia) merupakan bagian integral dari masyarakat (lingkungan). Dengan perkataan lain individu harus berkontribusi pada pengintegrasian masyarakat.

3. Fungsi diferensiasi

Fungsi diferensiasi, memandang bahwa program pendidikan nonformal harus memberikan pelayanan terhadap perbedaan-perbedaan individu dalam masyarakat. Hal ini berangkat dari suatu anggapan bahwa individu (lanjut usia) berbeda dengan individu (lanjut usia) lainnya. Perbedaan (diferensiasi di sini, dimungkinkan untuk bisa mendorong proses berpikir kritis dan komprehensif diantara individu (lanjut usia).

4. Fungsi persiapan

Fungsi persiapan, memantau memandang bawa program pendidikan nonformal harus berfungsi membersiapkan warga belajar untuk mampu melanjutkan dan atau menerima materi/bahan lebih jauh.

5. Fungsi pemilihan

Fungsi pemilihan, merupakan tindak lanjut dari fungsi perbedaan. Dimana dari perbedaan-perbedaan yang muncul harus mampu menarik dan menemukan pemilihan minat individu. (lanjut usia). 
6. Fungsi diagnostik

Fungsi diagnostik, memandang bahwa program pendidikan nonformal harus mampu mengarahkan warga belajar memahami dan menerima keadaan dirinya untuk dapat mendorong dan mengembangkan potensi yang dimilikinya.

\section{Prinsip Program Pendidikan Nonformal bagi Pendidikan Lanjut Usia}

Ada beberapa prinsip yang harus diketahui oleh warga belajar bagi masyarakat lanjut usia adalah sebagai berikut: (a) mempunyai keimanan, nilai-nilai moral dan berbudi pekerti yang luhur; (b) mengalami proses belajar sepanjang hayat (life long education); (c) mau berbagi dalam arti mengembangkan keterampilan kepada mereka yang membutuhkan; dan (d) mempunyai kemandirian hidup.

\section{Karakteristik Sasaran dan Aspek Penyelenggaraan Program bagi Lanjut Usia Karakteristik Kelompok}

Jumlah Kelompok

Anggota (warga belajar lanjut usia) pada umumnya orang tua yang umurnya rata-rata di atas umur 65 tahun ke atas. Mereka yang kelompok besar dibentuk dalam kelompokkelompok kecil yang terdiri dari beberapa orang. Biasanya mereka ini mempunyai minat dan bakat yang relatif sama serta memiliki kesukaan yang sama.

\section{Sifat Kelompok}

Mereka yang lanjut usia ini merukakan orang yang dianggap masih produktif dan masi mau untuk berkreativitas untuk mengerjakan kegiatan-kegiatan yang menghasilkan. Biasanya mereka cukup tekun dan ulet dalam mengerjakan pekerjaan tangan misalnya menyulam, membatik, menganyam dan sebagainya.

\section{Pengorganisasian Kelompok}

Warga belajar tidak dikelompokan berdasarkan minat terhadap salah satu satuan program, dari keseluruhan warga belajar diharapkan mengukuti seluruh kegiatan seandainya dilibatkan dalam program. Hal tersebut disebabkan keseluruhan materi belajar merupakan suatu bulatan yang utuh dan diharapkan menjadi bekal bagi warga belajar lanjut usia agar mandiri dalam menjalani kehidupannya.

\section{Karakteristik Warga Belajar}

1. Jumlah kelompok belajar tergantung pada besar kecilnya jumlah warga belajar, upayakan jumlah kelompok belajar tidak terlalu besar, maksimal 10 orang.

2. Latar belakang usia, pendidikan, sosial dan ekonomi, berkisar yang lanjut usia yang berumur di atas enam puluh tahun.

3. Jenis kelamin, laki-laki dan perempuan

\section{Prosedur Kerja Program Pendidikan Nonformal bagi Lanjut Usia}

Prosedur kerja pendidikan nonformal bagi lanjut usia meliputi langkah-langkah sebagai berikut. Pertama, perencanaan atau persiapan. Pada tahap ini, perencanaan adalah mempersiapkan dalam rangka pertemuan-pertemuan dengan pihak penyelenggara, pengurus maupun warga belajar lanjut usia serta unsur-unsur terkait. Pertemuan itu dimaksudkan 
sebagai upaya sosialisasi ide atau gagasan-gagasan yang bermanfaat. Program pendidikan nonformal ini perlu dilakukan agar dapat mencapai kemandirian warga belajar terhadap minat dan bakat yang mereka sukai.

Kedua, sosialisasi dipandang agar perlu pelaksanaan identifikasi kebutuhan dan kegiatan pengamatan sehingga berjalan dengan efektif dan efisien. Dalam program pendidikan nonformal perlu melibatkan orang-orang yang terkait terhadap program pendidikan lanjut usia seperti melibatkan warga belajar, sumber belajar, pekerja sosial, aparat pemerintahan, fasilitator ataupun instruktur pendidikan dan keterampilan yang dibutuhkan. Program pendidikan untuk masyarakat lanjut usia hendaknya menjadi perhatian kita bersama, terutama bahwa bereka ini dapat dijadikan sumber belajar, karena mereka mempunyai banyak pengalaman dan makna hidup yang cukup panjang.

\section{PEMBAHASAN}

\section{Materi dan Metode Untuk Pendidikan Nonformal}

Struktur materi program pendidikan nonformal bagi kelompok masyarakat lanjut usia adalah sebagai berikut:

1. Vocational and Carrier: Adjusting to retirement, Finding new ways to be useful, Understanding social security, medicare, and welfare.

2. Home and Family Living: Adjusting to reduced income, establishing new living arrangements, Learning to live alone, Reating to grandchildren, Establishing new intimate relationships, Putting your estate in order.

3. Personal Development: Developing compensantory abilities, understanding the aging procces, Reecamining your values, Keeping your morale up, Keeping up to date, Keeping in touch with young people, Keeping curious, Keeping up personal appearance, Keeping an open mind, Finding a new selp-identity, Developing a new time perspective, Preparing for death,

4. Enjoyment of leisure: Establishing affiliations with the older age group, Finding new hobbies, Learning new recreational skill, Planning a belanced recreational program.

5. Health: Adjusting to decreasing strength and health, Keeping fit, Changing your diet, Having regular medical exams, Getting appropriate, exercise, Using drugs and medicines wisely, Larning to deal with stress, Maintaining your reserves.

6. Community Living, Working for improved conditions for the elderly, Giving volunteer services, Maintaining organizational ties.

Metode dan teknik pelaksanaan program pendidikan nonformal bagi kelompok masyarakat lanjut usia, dipilih ke dalam langkah-langkah perencanaan, implementasi, dan evaluasi sebagai berikut:

\section{Perencanaan Program}

Perencanaan diawali dengan perumusan tujuan dengan mempertimbangkan kebutuhan warga belajar lanjut usia, pihak-pihak yang terlibat, sarana penunjang belajar, dan materi yang relevan serta biaya. Sedangkan langkah-langkah perencanaannya meliputi kegiatan sebagai berikut: (a) menentukan tujuan program; (b) menentukan bahan atau materi 
Pengelolaan Program Pendidikan Nonformal....

belajar dan pengorganisasiannya; (c) menentukan stategi pelaksasaan program kegiatan; (d) menentukan cara menilai hasil program/kegiatan.

\section{Impementasi Program}

Implementasi program di sini merupakan pelaksanaan program di lapangan. Program dalam pengertian kegiatan belajar bagi kelompok masyarakat lanjut usia setelah dalam taraf perencanaan yang matang, diwujudkan secara nyata di lapangan sehingga nantinya dapat memenuhi kebutuhan belajar kelompok masyarakat lanjut usia dalam upaya mencapai kemandiriannya. Ada beberapa unsur dalam strategi pelaksanaan pendidikan nonformal bagi kelompok masyarakat lanjut usia.

\section{Mengetahui Tingkat Kemampuan}

Mengetahui tingkat kemampuan warga belajar adalah sangat penting, karena akan diketahui sejauh mana tingkat pemahaman dan kemampuan dari masing-masing warga belajar, dan juga memberikan arah kebutuhan apa saja yang harus diberikan kepada mereka. Sekali pun dalam prakteknya, setiap warga belajar mendapat materi yang sama, namun dari segi strategi pelaksanaannya mendapat perbedaan.

\section{Mengefektifan Proses Belajar Mangajar}

Pelaksanaan program pada hakekatnya adalah mewujudkan program pendidikan nonformal supaya berfungsi memperbarui warga belajar menuju tercapainya tujuan yang telah dirumuskan. Bagaimanapun baiknya pendidikan nonformal, (kurikulum) tanpa dapat diwujudkan dan diupayakan mempengaruhi pribadi warga belajar, maka nilai-nilai yang terkandung di dalamnya menjadi sia-sia saja. Salah satu wujud nyata dari pelaksanaan program adalah proses belajar mengajar. Dengan perkataan lain, proses belajar mengajar adalah operasionalisasi dari program pendidikan nonformal dan program pembelajaran. Salah satu metode pelaksanaan pendidikan nonformal adalah mengefektifkan proses belajar yang selama ini dianggap proses belajarnya kurang efektif. Komponen-komponen pendidikan nonformal yang harus terdapat dalam mengefektifan proses belajar mengajar untuk untuk digerakkan supaya warga belajar mencapai tujuan program dan kemandirian warga belajar. Yakni: 1) Menyusun struktur materi belajar yang relevan dengan kebutuhan dan tujuan 2) Memilih metode pembelajaran yang tepat, dan 3) Mengadakan evaluasi yang baik dan terarah.

\section{Menetapkan Strategi Pembelajaran}

Ada beberapa strategi pembelajaran yang dianggap tepat untuk proses pembelajaran dalam masyarakat kelompok lanjut usia, di antaranya:

\section{Membentuk Kelompok-Kelompok Kecil}

Kelompok kecil dibentuk berdasarkan jenis kelamin warga belajar. Tujuannya dibentuk kelompok-kelompok kecil adalah supaya adanya ikatan emosional yang lebih erat sesama warga belajar dan untuk mengembangkan proses belajar yang lebih kondusif dan efektif. Setelah kelompok-kelompok kecil terbentuk, maka ditunjuk pemimpin kelompok. Pemimpin kelompok ditunjuk oleh peneliti berdasarkan keaktifan dan sifat tanggung jawab yang dimiliki serta saran-saran dari pihak pengelola dan anggota kelompok. 


\section{Partisipatif}

Partisipatif yang dimaksud di sini adalah upaya fasilitator/sumber belajar mengikutsertakan warga belajar dalam tahap pembelajaran, mulai dari perencanaan program, pelaksanaan program dan penilaian. Pada tahap perencanaan, warga belajar dilibatkan oleh peneliti dalam mengidentifikasi dan menjadi kebutuhan belajar mereka, memecahkan masalah, sumber-sumber yang tersedia dan hambatan-hambatan yang ditemui selama belajar. Pada tahap pelaksanaan, peneliti mengajak warga belajar untuk menciptakan iklim yang kondusif untuk belajar. Warga belajar diminta disiplin dalam masalah kehadiran, hubungan sesama warga belajar, dengan mengelola, membimbing, dan lingkungan diharapkan terciptanya hubungan kemanusiaan yang saling terbuka, saling menghargai dan saling membantu, saling belajar dan akrab. Pada tahap penilaian, pemimpin mengikutsertakan warga belajar dengan cara membantu untuk menghimpun dan menyampaikan informasi yang dapat digunakan sebagai bahan masukan penilaian terhadap hasil belajar. Strategi ditetapkan agar warga belajar merasa dekat, rasa kepedulian dan harapan untuk mandiri.

\section{$\underline{\text { Self-Directed Learning }}$}

Metode yang dipakai dengan harapan agar warga belajar dapat mengambil inisiatif dengan atau tanpa bantuan sumber belajar, dalam mendiagnosa kebutuhan belajar, mengidentifikasi sumber-sumber material dan memilih penerapan strategi belajar yang tepat dalam memilih penerapan strategi belajar yang tepat dalam rangka menilai hasil belajarnya sendiri.

Dari metode ini juga diharapkan tercipta iklim saling membelajarkan yang kondusif dan saling menyenangkan sesuai dengan karakter dan gaya masing-masing sehingga pada akhirnya tercipta suasana yang saling menguntungkan. Untuk itu penerapan strategi ini selalu memberhatikan konsep diri, pengalaman, kesiapan untuk belajar, dan materi serta tujuan yang sesuai dengan minat dan kebutuhan warga belajar sangatlah diperhatikan dan diutamakan.

\section{Bimbingan Terhadap Kelompok}

Proses belajar mengajar sebagai operasionalisaasi dari program pendidikan nonformal tidak selamanya berjalan seperti yang selalu diharapkan. Bahkan seringkali mengalami kegagalan, dalam arti warga belajar tidak dapat menguasai dan mencapai tujuan program. Kegagalan tersebut disebabkan oleh berbagai faktor, baik dari dalam maupun dari luar atau dari lingkungan warga belajar. Faktor yang terdapat dari dalam diri warga belajar seperti sakit-sakitan, kurang penglihatan atau pendengaran, gangguan mental misalnya lagi stress, emosinya terganggu, dan faktor psikologis lainnya, seperti kemampuan, minat dan kebiasaan. Sedangkan faktor luar dirinya antara lain keadaan keluarga, misalnya masalah ekonomi keluarga, adanya ketegangan sosial dalam rumah tangga dan lain sebagainya.

Faktor dan kondisi seperti di atas jelas tidak mendukung hasil belajar yang optimal, bahkan sebaliknya bisa menimbulkan kegagalan belajar. Oleh karena itu, kendala-kendala tersebut sedapat mungkin dapat diatasi sehingga memungkinkan warga belajar dapat mencapai tujuan belajarnya. Upaya mengatasi kendala tersebut, diusahakan melalui bimbingan yang ditangani oleh masing-masing pembimbing kelompok belajar. Bimbingan pada hakekatnya adalah proses bantuan khusus pada warga belajar dengan memperhatikan kemungkinan dan kenyataan tentang adanya kesulitan yang dihadapi dalam upaya mengembangkan pribadi dan kemandirian warga belajar sehingga mereka dapat memahami 
dirinya, mengarahkan sikap dan tindakannya sesuai dengan tuntutan dan keadaan lingkungan keluarga dan masyarakat. Bentuk bimbingan kepada warga belajar dalam program pendidikan nonformal adalah: 1) Bantuan terutama yang ditujukan untuk membantu kesulitan belajar dengan harapan warga belajar memperoleh hasil belajar yang optimal sesuai dengan potensi yang dimilikinya. 2) Bimbingan yang ditujukan untuk membantu warga belajar dalam memecahkan masalah pribadinya dengan menggunakan potensi yang ada pada dirinya.

\section{Menetapkan Hasil Belajar Yang Jelas}

Untuk menetapkan berhasil tidaknya warga belajar menjacai tujuan program pendidikan nonformal maka diperlukan kegiatan penilaian (evaluasi). Dengan adanya evaluasi dapat diketahui tingkat penguasaan tujuan pengajaran oleh warga belajar dalam membentuk hasil belajar yang dicapainya, dan juga dapat memberikan masukan kepada pengelola untuk memperbaiki proses belajar mengajar atau komponen program. Penilaian yang akan digunakan dalam program pendidikan nonformal adalah penilaian formatif yaitu penilaian yang dilakukan pada akhir program belajar. Tujuan penilaian adalah untuk memperbaiki komponen program dan kaitannya dengan sejauh mana tercapainya tujuan program.

\section{Evaluasi Program Pendidikan Pendidikan Nonformal}

Evaluasi program dimaksudkan untuk menilai dan menentukan efisiensi, efektivitas dan relevansi serta produktivitas pendidikan nonformal dalam mencapai tujuan yang telah ditetapkan. Efisiensi berkenaan dengan penggunaan waktu, tenaga dan sarana serta sumbersumber belajar lainnya secara optimal. Efektivitas berkaitan dengan penggunaan cara dan tepat dalam mencapai suatu tujuan. Relevansi berkenaan dengan kesesuaian sesuatu program dan pelaksanaannya dengan tuntutan dan kebutuhan warga belajar. Sedangkan produktivitas berkenaan dengan optimalnya hasil yang dicapai dari suatu program.

Evaluasi (penilaian) hasil belajar dilaksanakan pada akhir program kegiatan. Cara yang dilakukan menggunakan pendekatan kualitatif dan kuantitatif. Cara kuantitatif dipergunakan untuk mengetahui perbandingan hasil belajar antara kurikulum lama dengan model kurikulum baru dan pengaruh kurikulum baru terhadap kemandirian warga belajar berdasarkan angka-angka. Sedangkan secara kualitatif digunakan untuk menilai sifat-sifat dan tingkah laku warga belajar seperti kejujuran, tanggung jawab, disiplin, kreativitas, kesabaran, etos kerja, produktivitas, keceriaan, dan lain-lain. Alat yang digunakan dalam penilaian hasil belajar adalah berupa tes dan bukan tes. Tes yang akan digunakan adalah tes lisan dan tes tindakan.Sedangkan alat bukan tes adalah yakni berupa observasi, wawancara dan angket.

\section{KESIMPULAN}

Program pendidikan nonformal bagi masyarakat lanjut usia, perlu menjadi perhatian bersama, karena karakteristik dan potensi yang dimilikinya baik secara kuantitas maupun kualitas perlu diprogramkan sehingga pendidikan itu bisa berlangsung sepanjang hayat. Program pendidikan nonformal dalam memberdayakan kelompok masyarakat lanjut usia dapat mengimplementasikan secara efektif dan efisien sehingga berhasil guna.

Pengukuran keefektifan model pendidikan nonformal didasarkan pada: a) tingkat penerimaan sumber belajar (fasilitator atau pengelola) dan peserta program (kelompok masyarakat lanjut usia) terhadap program pendidikan nonformal diharapkan mendapatkan 
respon yang cukup tinggi, karena masih banyak kelompok manyarakat yang lanjut usia belum mendapat perhatian. Pendidikan itu berlangsung sepanjang hayat.

\section{DAFTAR RUJUKAN}

Atch, R.C. (2000). The Social Forces in Later Life Introduction to Social Gerontology, Second Education. California: Publishing Company.

Bustamam H.D. (2002) Hidup Bermakna di Lanjut Usia: Sebuah Pendekatan Psikologi. Jakarta: Departemen Kesehatan RI.

Gray, D. Glaffin C \& Nasta, T. (2001). Training to Teach in Futher and Adult Education. United Kingdom: Nelson Thornes Limited.

Haditono, S.R. (2003). Kesulitan-Kesulitan Belajar. Yogyakarta: Gunung Agung

Hamalik, O. (2007). Sistem dan Prosedur Pengembangan Kurikulum Lembaga Pendidikan dan Pelatihan. Bandung: Trigenda Karya.

Javis, P. (2000). Adult and Continiung Education: Theory and Practice. Newyork: Nichols Publishing Company.

Latenoh,T. (2000). Gerontologi dan Pelayanan Lanjut Usia. Bandung: Antaba Press.

Kidervater, Suzanne. (1979). Nonformal Edunation as an Empowering Process Center for International Education. Amherst.

Lunandi, A.G. (1989). Pendidikan Orang Dewasa. Jakarta: Gramedia.

Permutter, M. (1985). Adult Development an Agin. United State of America: John Wiley \& Sons, Inc. 